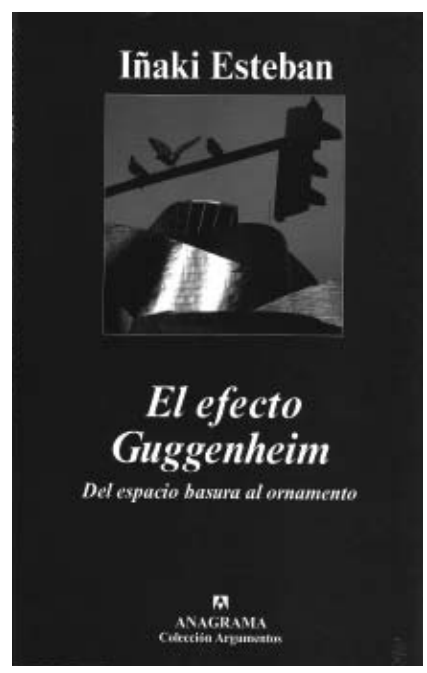

Iñaki Esteban

\section{El efecto Guggenheim, del espacio basura al ornamento}

Barcelona: Editorial Anagrama (2007)
"El efecto Guggenheim, del espacio basura al ornamento" es el título que el autor utiliza para introducirse en el análisis del "ornamento" como un fenómeno social que se instrumentaliza a través de la cultura. En este caso, la institución de un museo que se enmarca en el contexto de una "nueva fase del capitalismo informacional, estetizante y globalizador", donde el símbolo de la innovación en las ciudades se ha trasladado desde los negocios o las instituciones políticas, a la cultura.

A partir de la elaboración del concepto de "ornamento", se explica la operación de regeneración de un "espacio basura” y los beneficios que esto ha significado para la ciudad de Bilbao, cuestionando si el Guggenheim es realmente un museo o si, por el contrario, responde a otros intereses y criterios en su condición de ornamento, cumpliendo con funciones extraculturales que nacen de una iniciativa política para "estetizar una ciudad brusca, feísta y en crisis” y, así, posicionar a la ciudad en la esfera internacional.

Para entender el espacio basura, el autor se basa en la definición de Rem Koolhaas en la que el espacio basura "se convierte en una suerte de concepto-contenedor en el que cabe todo, los diamantes y los desperdicios... describiría una arquitectura de usar y tirar, o de usar y reacondicionar" (p. 38). Sólo que en el caso del Guggenheim no estamos hablando de un edificio que se convierte en basura, sino de un espacio entero que ocupaba y rodeaba esa zona. En este contexto el espacio basura señala la merma de valor de uso de una parte céntrica de la ciudad cuya actividad industrial pierde su función generando deterioro a su alrededor.

En el primer capítulo, el autor construye una teoría del "ornamento" como concepto que explica y caracteriza la naturaleza del Guggenheim, donde "la arquitectura y lo bello no son inútiles si se entienden como una inversión estratégica para mover la evolución urbana”. Al ser visto como ornamento, el Guggenheim cumple una función extracultural trasformándose un "recurso que crea urbanismo, imagen y comunicación, actividad económica y lealtad política” (p. 17) y cuyo papel es el de comunicar el nuevo estatus de la ciudad y su atractivo como destino turístico. 
El término ornamento tiene una connotación de inútil o ajeno a lo funcional. Un museo como infraestructura no sería necesario para el funcionamiento de la ciudad, pero si se implanta con éxito y cumple con las mencionadas funciones extraculturales, la ciudad se desarrolla, crece y se enriquece. Como infraestructura el ornamento debe llamar la atención para dotar de visibilidad e identidad a la ciudad, transformándose, así, en algo funcional y productivo. De esta manera, las características del ornamento se pueden establecer en las siguientes funciones:

1) urbanística, donde la regeneración urbana y su énfasis estético y sensorial sirven para crear una imagen de ciudad abierta a lo novedoso, al lujo y a la moda. Es decir, un lugar chic que llama la atención;

2) económica, el ornamento aporta competitividad eliminando la distancia entre lo global y lo local, se inserta en una sociedad de la comunicación donde importan más los escenarios que los contenidos: el escenario ornamental atrae turistas y fomenta el desarrollo de actividades relacionadas;

3) política, los ciudadanos lo interiorizan como un símbolo que los acerca a la innovación global, se genera cohesión y consenso ciudadano asociados a los valores de lo positivo, de progreso, de confianza y de modernidad. La clase política contribuye a crear este consenso y pretende que el votante identifique el éxito del ornamento con el de su partido. Para los políticos, la creación de una infraestructura con poder de irradiación los justifica y fomenta la lealtad ciudadana;

4) por último el ornamento se transforma en una "máquina de relaciones públicas", que en la confluencia de los intereses económicos y políticos, actúa como pantalla para la imagen y los mensajes interesados de partidos políticos, instituciones y empresas (pp. 20-22).

Sin embargo, el Guggenheim encuentra legitimidad en la función cultural como mecanismo de autojustificación, acercándose a un "ideal de cultura" en la que su valor se mide por su capacidad de dinamizar la economía y la política, teniendo como centro gravitacional la rentabilidad tangible de esferas, en principio, extraculturales asociadas al dinero y el poder. Por lo tanto, en los siguientes capítulos el autor desarrolla la idea de que el Guggenheim representa un modelo de cultura extracultural y economicista derivado más que nada de intereses políticos, que genera beneficios inmateriales (segundo capítulo) mediante una infraestructura "cultural" en la que el arte cumple un rol secundario (tercer capítulo) y que se transforma en un escenario político (cuarto capítulo).

La base del segundo capítulo se sustenta en que la "ornamentalidad" explicaría los beneficios y las dinámicas que se han generado alrededor de este museo del siglo XXI. La "operación estética" se transforma en una estrategia inmaterialista -cultural- de gran éxito. Mediante un esquema de recuperación a través de una infraestructura cultural se logra un empuje inmaterial -anímico- de un ornamento con contraprestaciones materiales, económicas y políticas.

La transformación del espacio basura en ornamento se levanta como una bandera de ilusión y entusiasmo que genera un clima propicio para el desarrollo económico. Capitalizar la ilusión de la gente es una gran fuente de beneficios. En la medida que el ornamento ha cumplido con éxito sus funciones extraculturales, el grado de optimismo de los ciudadanos ha mejorado. Si se acepta como axioma económico que el optimismo redunda en un mayor consumo, la ola 
de optimismo generado por el Guggenheim ha creado efectos beneficiosos que se transforman en uno de los elementos legitimizadores del ornamento.

Lo anterior hace referencia al efecto económico generado por los mismos ciudadanos, sin embargo, la función económica del ornamento reside principalmente en la atracción de turistas. La regeneración urbanística con la cultura como pivote y el turismo se complementan. La ola de turistas genera por si misma una reorientación y revitalización económica. Para lograr atraer turistas el autor explica que "un ornamento como el Guggenheim debe tener la suficiente singularidad para atraer el turismo en una civilización transitada por la competencia entre imágenes" (p. 53). Luego, una ciudad que aspire a ser un destino turístico y que no tenga un ornamento reseńable no es competitiva.

Económicamente, el Guggenheim posibilita y potencia el paso del sector productivo a la era de los servicios y el know how, donde el ocio y la cultura se transforman en un negocio. El Guggenheim se construye para regenerar el tejido urbano y económico, y su mayor legitimidad reside en el beneficio derivado de la atracción de turistas. Por lo tanto, su arquitectura y su programa están en función de dichos beneficios. Económicamente hablando, al ornamento se le exige rentabilidad, como se explica en el tercer capítulo.

A partir de las consideraciones anteriores, en el tercer capítulo se pone en duda si el Guggenheim responde al modelo tradicional de museo. A partir de la teoría del ornamento el autor muestra que a pesar de que el Guggenheim se estructura en torno a la cultura que se materializa en la implantación de la infraestructura-museo, sus objetivos consisten en dinamizar la economía y la política, quedando el arte relegado a una posición secundaria.

El Guggenheim se presenta como un modelo de gestión que tiene que mostrar su capacidad de generar recursos y ejemplificar un tipo de institución cultural no dependiente de los recursos públicos, aunque termine en una sumisión plena al poder político como se explicará en el cuarto capítulo. Se transforma en una institución que tiene que administrar su programa como ornamento y para ello "moviliza su atractivo comercial, se preocupa del patrocinio y visualiza el apoyo de las empresas, atiende los requerimientos de los políticos y cuida de su imagen, activando mecanismos de los medios de comunicación” (p. 71). Las funciones del ornamento obligan a que la gestión prevalezca sobre los principios estéticos.

El espectáculo del Guggenheim reside en su condición ornamental, en su ilusión, en su producción de consenso y de una visión del mundo asociado al lujo, en su capacidad de regenerar el tejido urbano, mejorar el animo ciudadano o constituir espacios de aclamación política por la mediación de su imagen, convertida en logotipo (p. 92). Por lo anterior, la función de museo propiamente tal no es de gran relevancia y ello se ve reflejado en el tipo de muestras que se organizan.

El programa expositivo del Guggenheim está determinado por la movilidad, circulación y transformación de las muestras como estrategia globalizadora, en vez de una colección propia que actúe como núcleo que otorga identidad a un museo en su concepción tradicional. Esta estrategia responde a su condición de sucursal de una constelación de museos con base en 
Nueva York que busca reducir costos, transformando al museo en un punto de distribución. La función del ornamento se cumple mejor con muestras temporales por la rentabilidad obtenida de las economías de escala implícitas en esta estrategia.

El museo como ornamento excede por mucho al arte por el arte. El Guggenheim evidencia una visión comercial y de marketing relacionada con la primacía del discurso gestor antes mencionado y con el ideal de autofinanciación. Las muestras se transforman en mercancías y el visitante en un cliente que consume la oferta del arte convertido en marca identitaria (de masas). El museo transformado en ornamento se convierte en "un símbolo devenido del merchandising con un toque de sofisticación” (p. 93).

Finalmente, como anuncia el título del cuarto capítulo, el museo se transforma en un "escenario de aclamación política". Los ornamentos como el Guggenheim cumplen una función importante en la escenografía política, donde vale más la foto en el marco ornamental-imagen positiva- que cualquier mensaje. En esta nueva estetización de la política, los actos culturales y sus escenografías cumplen el papel de dar prestigio e imagen al poder político y a sus aliados económicos.

En el tránsito de una sociedad burguesa a una sociedad de masas, el lujo ha perdido su carácter de privilegiado y cualquiera puede acceder a él gracias a las políticas del bienestar. Aquí entra en juego lo que podría llamarse "lujo institucional". En la esencia de la sociedad contemporánea se ha instalado lo superfluo, los acontecimientos y las presentaciones de un ornamento revelan una sociedad de las apariencias y las ilusiones. Las masas ya no se contentan con el bienestar básico, exigen al Estado que financie el lujo que necesita esta sociedad de la abundancia.

La ciudadanía reclama recompensas a los poderes públicos a cambio de su adhesión y lealtad. Los políticos vascos respondieron a estas demandas con el edificio del arquitecto de firma Frank Gehry para actuar en el nuevo escenario de relación mediática con los votantes, entendiendo que era necesario proveer a los votantes del "lujo institucional" que reclaman. Por lo anterior el autor afirma que "el poder propicia el ornamento e incluso lo necesita" (p. 106), mediante la operación estética llevada a cabo por el poder político que capitaliza la transformación del espacio basura en ornamento, logrando consenso y lealtad en la ciudadanía.

El consenso político que genera el Guggenheim lo encumbra como "algo bueno para el país". Amparados en esta idea, cada partido viste al ornamento con ideas propias y lo caracterizan a su conveniencia para distinguirse en el entorno electoral. Los nacionalistas destacan que el Guggenheim nace del dinamismo y la visión de futuro de sus propias instituciones, los socialistas lo adornan con la idea de progreso, de futuro y de servicio público, en tanto los conservadores lo ven como un ejemplo de financiación mixta, método que habría que profundizar hasta conseguir la plena autofinanciación del museo. Finalmente el Guggenheim se transforma en un símbolo del país a la altura de los tiempos, que ha cumplido con el objetivo de "proyectar una imagen internacional para Bilbao y el País Vasco” (p. 113), un logro que afirma el discurso populista de independencia de Espańa y plasma con éxito una visión de país. 
El "efecto" Guggenheim demuestra el potencial simbólico de la arquitectura y su capacidad para producir identidad. Así, el museo no es tanto un lugar de uso sino que se transforma en un símbolo que suscita consenso. Es el espejo de la satisfacción y el bienestar. No hace falta usar el Guggenheim, sólo basta con admirarlo y sentirse orgullosos de él. La utilización escasa no resta al ornamento su potencial y atractivo simbólico. El museo visto como ornamento ya no funciona solo como desarrollo desinteresado del saber, sino también como catalizador, punto de encuentro y escenario de sueños, ilusiones, esperanzas e intereses de los ciudadanos (p. 139).

A lo largo del libro, el concepto ornamento se transforma en el eje central del argumento. El Guggenheim visto como ornamento da cuenta de un fenómeno que se genera en torno a una infraestructura cultural que logra revitalizar a la ciudad en los aspectos urbanísticos, por la regeneración urbana de una zona deteriorada; económicos, con la atracción de visitantes que dinamizan la economía; y sociales, porque logra un sentimiento de orgullo e identidad en sus habitantes. A diferencia de otras iniciativas comparables a nivel mundial, como los docks de Londres, el Guggenheim es un ornamento controlado por la política y no por el mercado, con lo que se logra dotar a las instituciones de mayor capacidad de intervención en la ciudad y es el ejemplo de una nueva tendencia de innovación en las ciudades basada en la cultura, que logra involucrar al ciudadano que resulta ser el principal beneficiario.

Ángela Palma*

Ingeniero Comercial, Magíster en Desarrollo Urbano, Instituto de Estudios y Territoriales, Pontificia Universidad Católica de Chile. E-mail: apalma1@uc.cl 